\title{
層状複水酸化物の熱分解物による 芳香族スルホン酸イオンの吸着
}

(1992 年 1 月 10 日受理)

成田榮 - * • 山岸俊秀・鈴木和子

\section{1 緒言}

層状複水酸化物（以下，LDH と略記する）は，その特異な陰 イオン交換能から最近注目されている層状の不定比化合物であ り，つぎの一般式であらわされる1) 5)。

$$
\left[\mathrm{M}^{2+}{ }_{1-x} \mathrm{M}^{3+}{ }_{x}(\mathrm{OH})_{2}\right]^{x+}\left[\mathrm{A}^{n-}{ }_{x / n} \cdot y \mathrm{H}_{2} \mathrm{O}\right]^{x-}
$$

ここで, $\mathrm{M}^{2+}$ は $\mathrm{Mg}^{2+}, \mathrm{Ni}^{2+}, \mathrm{Zn}^{2+}$ などの二価金属イオン, $\mathrm{M}^{3+}$ は $\mathrm{Al}^{3+}, \mathrm{Cr}^{3+}, \mathrm{Fe}^{3+}$ などの三価金属イオン, $\mathrm{A}^{n-}$ は $\mathrm{OH}^{-}$, $\mathrm{Cl}^{-}, \mathrm{CO}_{3}{ }^{2-}$ などの $n$ 価の陰イオンで, $x$ は一般に $0.2 \sim 0.33$ の 範囲である。結晶構造は, 正の電荷をもつ正八面体の brucite が 並んだ二次元基本層と負の電荷をもつ中間增からなる積䅉構造を とっている。陰イオン性粘土鉣物として天然にもいくつか存在し ていることが知られており，合成も比較的簡単である。このう ち，Mg-Al 系炭酸型 LDH はハイドロタルサイトとして知られ, 合成と物理化学的性質についてはいくつかの報告がなされてい る(6) そ2)。なかでュニークな性質として，500～800 ${ }^{\circ} \mathrm{C}$ の温度 で（1）式のように熱分解して, 岩塩型の酸化マグネシウムーア ルミニウム固溶体となり，これを水中に添加すると（2）式のよ らに共存する陰イオンと水分子を取り込んで, 再び層状の LDH 構造を形成することが知られている（口は vacancy $)^{8) 13) 。 ~}$

$\left[\mathrm{Mg}_{1-x} \mathrm{Al}_{x}(\mathrm{OH})_{2}\right]\left(\mathrm{CO}_{3}\right)_{x / 2}$

$=(1+x / 2) \mathrm{Mg}_{2(1-x) /(2+x)} \mathrm{Al}_{2 x /(2+x)} \square_{x /(2+x)} \mathrm{O}+x / 2 \mathrm{CO}_{2}+\mathrm{H}_{2} \mathrm{O}$

八戸工業高等専門学校物質工学科, 039-11 八戸市田面木 字上野平

1) C. Frondel, Am. Mineral., 26, 295(1941).

2) M. C. Gastuche, G. Brown, M. M. Mortland, Clay Miner., 7, 177(1967).

3) R. Allmann, Acta Cryst., B 24, 972(1968).

4) H. F.W. Taylor, Mineral. Mag., 39, 377(1973).

5) G.W. Brindley, S. Kikkawa, Am. Mineral., 64, 836 (1979).

6) W. Feitknecht, M. Gerber, Helv. Chim. Acta, 25, 131(1942).

7) S. Miyata, T.Kumura, Chem. Lett., 1973, 843.

8) S. Miyata, Clays Clay Miner., 28, 50(1980).

9) S. Miyata, ibid., 31, 305(1983).

10) W. T. Reichle, Solid States Ionics, 22, 135(1986).

11) W. T. Reichle, CHEMTECH, Jan., 58(1986).

12）宮田茂男, 石高と右灰, No.187, 333(1983); ゼオライト, 8, 7(1991).

13) T. Sato, T. Wakabayashi, M. Shimada, Ind. Eng. Chem. Prod. Res, Dev., 25, 89(1986). $(1+x / 2) \mathrm{Mg}_{2(1-x) /(2+x)} \mathrm{Al}_{2 x /(2+x)} \square x /(2+x) \mathrm{O}+x / n \mathrm{~A}^{n-}$

$$
+(1+x / 2) \mathrm{H}_{2} \mathrm{O}=\left[\mathrm{Mg}_{1-x} \mathrm{Al}_{x}(\mathrm{OH})_{2}\right] \mathrm{A}_{x / n}+x \mathrm{OH}^{-}
$$

これらの反応に基づく $\mathrm{Mg}-\mathrm{Al}$ 系 $\mathrm{LDH}$ の熱分解物による陰イオ ンの吸着*としては，これまで各種の無機オキソ酸13) 15)，七バシ ン酸16), 各種の脂肪族モノおよびジカルボン酸17)，グルタミン 酸 ${ }^{18)}$ について調べられている。また, 上記のような熱分解-再水 和反応を示す炭酸型 $\mathrm{LDH}$ として, $\mathrm{Mg}-\mathrm{Fe}$ 系 ${ }^{19)}, \mathrm{Co}-\mathrm{Al}$ 系 ${ }^{19}$ お よび $\mathrm{Zn}-\mathrm{Al}$ 系 ${ }^{20)}$ が知られているが，詳しい検討はなされておら ず, 特に有機陰イオンの吸着については研究例がない。そこで, 本研究では, ゲスト陰イオンとして芳香族スルホン酸イオンを取 り上げ， $\mathrm{Mg}-\mathrm{A} 1$ 系と $\mathrm{Zn}-\mathrm{Al}$ 系の炭酸型 $\mathrm{LDH}$ の熱分解-再水和 反応に基づく有機陰イオンの吸着特性について比較・検討を行っ た。

\section{2 実験}

\section{1 炭酸型 LDH および LDH 熱分解物の合成}

実験に用いた試薬はすべて市肘特級試薬である。 $\mathrm{Mg}-\mathrm{Al}$ 系炭 酸型 LDH の合成は, 宮田の方法 ${ }^{8}$ に準拠して行った。すなわち, $0.5 \mathrm{M}$ の $\mathrm{MgCl}_{2}-\mathrm{AlCl}_{3}$ 混合溶液 $\left(\mathrm{Mg}^{2+} / \mathrm{Al}^{3+}=2\right)$ を $0.2 \mathrm{M} \mathrm{Na}$ $\mathrm{OH}$ で $\mathrm{pH} 10$ に保ちながら $0.02 \mathrm{M} \mathrm{Na}_{2} \mathrm{CO}_{3}$ 溶液に $\mathrm{CO}_{3}{ }^{2-} / \mathrm{Al}^{3+}$ $=0.7$ になるまでかきまぜながら滴下した。反応温度は $60^{\circ} \mathrm{C}$ と し, 滴下後もそのままの状態で 1 時間熟成を行った。 $\mathrm{Zn}-\mathrm{Al}$ 系炭 酸型 $\mathrm{LDH}$ 合成は, 試薬濃度を上記の半分にした以外は同様にし て行った。生成物は十分水洗したのち，60 ${ }^{\circ} \mathrm{C} て ゙$ 乾燥した。生 成物の組成分析は既報 ${ }^{21)}$ と同様に行い, それぞれ $\left[\mathrm{Mg}_{0.72} \mathrm{Al}_{0.28}\right.$ ・ $\left.(\mathrm{OH})_{2}\left(\mathrm{CO}_{3}\right)_{0.14} \cdot 0.24 \mathrm{H}_{2} \mathrm{O}\right]$ と $\left[\mathrm{Zn}_{0.70} \mathrm{Al}_{0.30}(\mathrm{OH})_{2}\left(\mathrm{CO}_{3}\right)_{0.15} \cdot 0.72\right.$

* 化合物生成にともなう「取り込み」現象であるが，ここで は便宜上吸着とした。

14) T. Sato, M. Tezuka, T. Endo, M. Shimada, Reac. Solids, 3, 287(1987).

15) K. Chibwe, W. Jones, Chem. Mater., 1, 489(1989).

16) K. Chibew, W. Jones, J.Chem.Soc., Chem. Commun., 1989, 926.

17) E. Narita, T. Yamagishi, Proc. 9 th Int. Clay Conf., Strasbourg, 1989, Sci. Géol. Mém., 86, 145(1990).

18）成田榮一, 山岸俊秀, 八戸工業高等専門学校廃寨物 ・ $ネ$ ルギー利用教育研究センター報告, 8, 7(1990).

19) T.Sato, H. Fujita, T.Endo, M.Shimada, Reac. Solids, 5, 219(1988).

20) E. Narita, P. Kaviratna, T. J. Pinnavaia, Chem. Lett., $1991,805$.

21）成田榮一, 山岸俊秀, 秘内辰夫, 日化, 1992, 291. 
$\left.\mathrm{H}_{2} \mathrm{O}\right]$ であった。熱分解物 $\left(\mathrm{Mg}_{0.72} \mathrm{Al}_{0.28} \square_{0.14} \mathrm{O}\right.$ および $\mathrm{Zn}_{0.70}$ $\left.\mathrm{Al}_{0.30} \square_{0.16} \mathrm{O}\right)$ は, 得られた $\mathrm{LDH}$ を $500^{\circ} \mathrm{C}$ で 2 時間加熱するこ とによって調製した。

\section{2 芳香族スルホン酸イオンの吸着}

被吸着物質としては, 2-ナフトールー3,6-ジスルホン酸ナトリ ウム（以下, NDS と略記する）と $m$-ベンゼンジスルホン酸ナ トリウム（以下，BDS と略記する）の 2 種を取り上げた。吸着 実験は, 所定量の芳香族スルホン酸イオンを含む水溶液 $50 \mathrm{~cm}^{3}$ を内容積 $0.1 \mathrm{dm}^{3}$ の栓付三角フラスコに入れ, これに熱分解物 $0.2 \mathrm{~g}$ を添加したのち, $\mathrm{pH}$ の調整を行らことなく $25^{\circ} \mathrm{C}$ で 20 時間ふりまぜることによって行った（16 時間で平衡に到達）。吸 着後の眯濁液を遠心分離し, 上澄み液については, 島津製作所製 全有機炭素計 TOC-500 型を用いて芳香族スルホン酸イオンの濃 度を測定した。吸着量は吸着前後の濃度差から求めた。固体生成 物は, 水洗し, $60^{\circ} \mathrm{C}$ で乾燥したのち, 既報 ${ }^{21)}$ と同じく粉末 X 線 回折によって検討を行った。

\section{3 結 果と考察}

\section{1 炭酸型 LDH の熱分解}

2.1 において得られた $\mathrm{Mg}-\mathrm{Al}$ 系と $\mathrm{Zn}-\mathrm{Al}$ 系の炭酸型 $\mathrm{LDH}$ およびそれらの熱分解物の粉末 X線回折図を図 1 に示す。 $60^{\circ} \mathrm{C}$ 乾燥物については, いずれの場合も典型的な $\mathrm{LDH}$ 構造 $\left(d_{003}=\right.$ $7.7 \AA)$ を示しているが, $500{ }^{\circ} \mathrm{C}$ 加熱物には違いが認められた。 すなわち、 $\mathrm{Mg}-\mathrm{Al}$ 系では $2 \theta=43.3^{\circ}$ に岩塩型構造に基づくブ ロードな回折ピークが現れるのに対し，Zn-Al 系では $2 \theta=31 〜$ $37^{\circ}$ に Zincite $(\mathrm{ZnO})^{22)}$ および Gahnite $\left(\mathrm{ZnO} \cdot \mathrm{Al}_{2} \mathrm{O}_{3}\right)^{23)}$ の前駆 体と考えられるブロードな回折ピークが現れた。TG-DTA によ れば, $\mathrm{Mg}-\mathrm{Al}$ 系より $\mathrm{Zn}-\mathrm{Al}$ 系の方がより低い温度で層間水の脱 離や脱炭酸が起こることが観察された。このことは, $\mathrm{Zn}-\mathrm{Al}$ 系の 方が加熱による LDH 構造の破壊と酸化物への再結晶化が進みや すいことを示唆している。図 1 からもわかるように, Zn-Al 系の 場合, $900^{\circ} \mathrm{C}$ でZincite と Gahnite に変化しているのに対し,

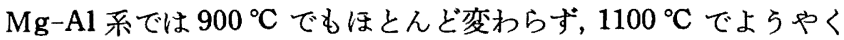
Periclase $(\mathrm{MgO})^{24)}$ と Spinel $\left(\mathrm{MgO} \cdot \mathrm{Al}_{2} \mathrm{O}_{3}\right)^{25)}$ に変化している。 $\mathrm{Mg}-\mathrm{Al}$ 系と同様, $\mathrm{Co}-\mathrm{Al}$ 系と $\mathrm{Ni}-\mathrm{Al}$ 系の炭酸型 $\mathrm{LDH}$ の熱分解 挙動については，すでに調べられているが19)，脱炭酸の起こる温 度を比較すると, $\mathrm{Co}-\mathrm{Al}$ 系 $<\mathrm{Ni}-\mathrm{Al}$ 系 $<\mathrm{Zn}-\mathrm{Al}$ 系 $<\mathrm{Mg}-\mathrm{Al}$ 系の 順に二価金属イオンの塩基度に応じて高くなることがわかった。

\section{2 芳香族スルホン酸イオンの吸着等温線}

$\mathrm{Mg}-\mathrm{Al}$ 系および $\mathrm{Zn}-\mathrm{Al}$ 系の炭酸型 $\mathrm{LDH}$ の熱分解物による NDS と BDS の吸着等温線を図 2 にまとめて示す。いずれの熱 分解物も BDS よりは NDS に対する吸着能が大きく, その差は $\mathrm{Zn}-\mathrm{Al}$ 系の方が顕著であった。無機陰イオンの場合は, 電荷密度 の大きなものほど吸着されやすいことが知られているが13)，本実 験の場合は逆の結果となった。脂肪族カルボン酸イオンの場合に は,ゲスト陰イオン同士の van der Waals 力による引きつけのた

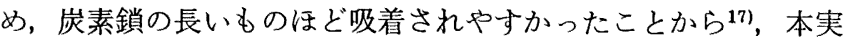
験の結果も同じくベンゼン環同士よりもナフタレン環同士の方が

22) ASTM-card 5-0664.

23) ASTM-card 5-0669.

24) ASTM-card 4-0829.

25) ASTM-card 5-0672.

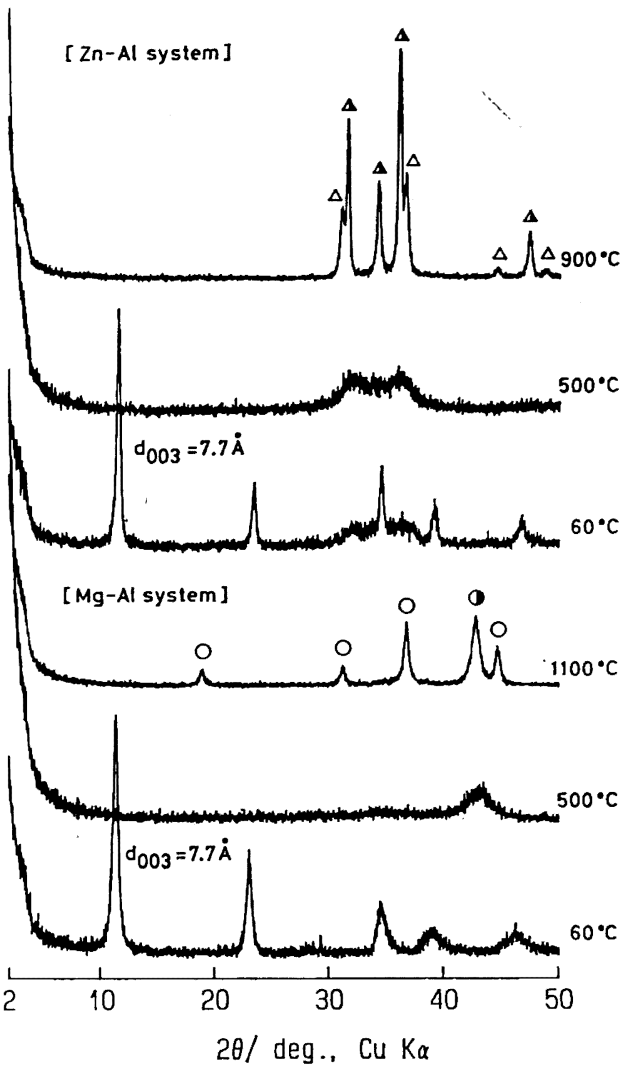

Fig. $1 \mathrm{X}$-Ray diffraction patterns for $\left[\mathrm{Mg}_{0.72} \mathrm{Al}_{\mathbf{0 . 2 8}}\right.$. $\left.(\mathrm{OH})_{2}\left(\mathrm{CO}_{3}\right)_{0.14} \cdot 0.24 \mathrm{H}_{2} \mathrm{O}\right]$ and $\left[\mathrm{Zn}_{0.70} \mathrm{Al}_{0.30}(\mathrm{OH})_{2}\right.$. $\left.\left(\mathrm{CO}_{3}\right)_{0.15} \cdot 0.72 \mathrm{H}_{2} \mathrm{O}\right]$ and for the products formed by calcining at various temperatures in air for $2 \mathrm{~h}$

$\bigcirc$ : Spinel $\left(\mathrm{MgO} \cdot \mathrm{Al}_{2} \mathrm{O}_{3}\right), \quad$ : Periclase $(\mathrm{MgO})$,

$\triangle$ : Gahnite $\left(\mathrm{ZnO} \cdot \mathrm{Al}_{2} \mathrm{O}_{3}\right), \boldsymbol{\Delta}:$ Zincite $(\mathrm{ZnO})$

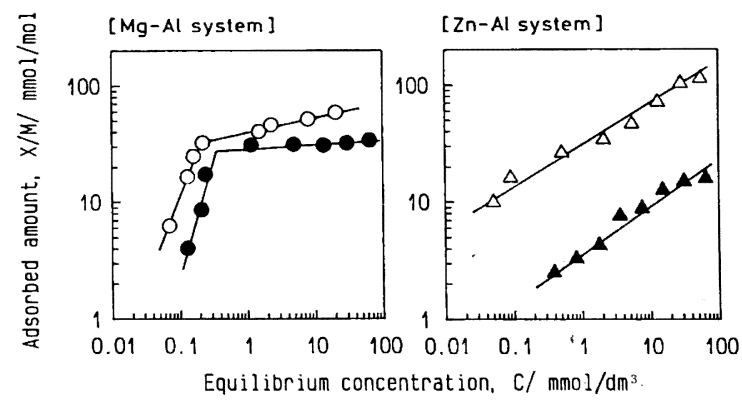

Fig. 2 Adsorption isotherms of NDS ion $(O, \triangle)$ and BDS ion (, $\boldsymbol{\Delta})$ with the oxide solid solutions at $25{ }^{\circ} \mathrm{C}$

引きつけが大きいため吸着されやすいものと考えられた。さら に, ホスト層の構成元素の違いによる吸着特性にはいちじるしい 違いが認められた。すなわち, $\mathrm{Zn}-\mathrm{Al}$ 系の場合には直線の吸着等 温線が得られたが, $\mathrm{Mg}-\mathrm{Al}$ 系の場合には平衡濃度 $0.2 \sim 0.3 \mathrm{~mol}$ ・ $\mathrm{dm}^{-3}$ 付近で折れ曲がった吸着等温線となった。これは, 熱分解 物の一部が溶解し，それぞれ平衡 $\mathrm{pH}$ が異なることに起因してい ると考えられた。水溶液中には陰イオンとして芳香族スルホン酸 イオンのほか水酸化物イオンが共存し，（2）式の再水和反応で は両者のイオンの競争反応となる。吸着後の溶液 $\mathrm{pH}$ を表 1 に示 したが， Mg-Al 系の方が $\mathrm{Zn}-\mathrm{Al}$ 系よりも $\mathrm{pH}$ が高い。したがっ 
Table 1 Adsorption data of NDS and BDS ions with the oxide solid solutions at $25^{\circ} \mathrm{C}$

\begin{tabular}{|c|c|c|c|c|}
\hline \multirow[b]{2}{*}{$\mathrm{LDH}$} & \multirow[b]{2}{*}{$\begin{array}{r}\text { Adsorb- } \\
\text { ate }\end{array}$} & \multirow{2}{*}{$\begin{array}{c}\text { Equilib- } \\
\text { rium } \\
\mathrm{pH}\end{array}$} & \multicolumn{2}{|c|}{$\begin{array}{l}\text { Freundlich's } \\
\text { parameters }\end{array}$} \\
\hline & & & $k\left(\begin{array}{c}\mathrm{mmol} / \\
\mathrm{mol})\end{array}\right.$ & $n(-)$ \\
\hline \multirow{2}{*}{$\mathrm{Mg}-\mathrm{Al}$ system } & NDS & $11 \sim 12$ & 42.0 & 6.5 \\
\hline & BDS & $11 \sim 12$ & 11.3 & 8.3 \\
\hline \multirow{2}{*}{$\mathrm{Zn}-\mathrm{Al}$ system } & NDS & $9 \sim 10$ & 32.1 & 3.3 \\
\hline & BDS & $9 \sim 10$ & 4.4 & 2.7 \\
\hline
\end{tabular}

て, $\mathrm{Mg}-\mathrm{Al}$ 系の場合のみ, 芳香族スルホン酸イオンの平衡濃度 が低い領域では水酸化物イオンの方が吸着されやすくなり，折れ 曲がった吸着等温線になったものと考えられた。 $\mathrm{Mg}-\mathrm{Al}$ 系では $0.2 \mathrm{~mol} \cdot \mathrm{dm}^{-3}$ 以上, $\mathrm{Zn}-\mathrm{Al}$ 系では測定範囲の平衡濃度に㧍ける

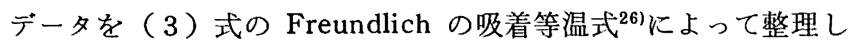
た。

$$
\log (X / M)=1 / n(\log C)+\log k
$$

ここで, $X$ : 吸着量 $(\mathrm{mg}), M$ : 吸着剂の添加量 $(\mathrm{g}), C:$ 平 衡濃度 $\left(\mathrm{mg} \cdot \mathrm{dm}^{-3}\right), n$ と $k$ は定数である。その結果を表 1 に示 す。いずれの場合も $n$ 值が 2 以上となり, 吸着剤として優れてい ることがわかった。

吸着後の固体生成物はすべて LDH 構造をもっていることが確 認された。一例として, 図 3 KDS 吸着後の固体生成物のX線 回折図を示す。いずれの系でも, 吸着量の少ない場合は層間距離

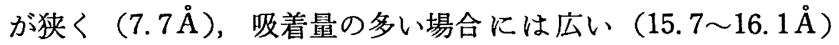
$\mathrm{LDH}$ となった。前者ではゲスト陰イオンはおもに水酸化物イオ ンであり, 少量取り込まれた NDSイオンの配位状態については 明確なことはいえないが, 飽和脂肪族カルボン酸イオンの同様な 場合は基本層に対して平行に取り込まれたこと ${ }^{17)}$, 図 3-a の結晶 化度が高いことから, 平行に取り込まれている可能性が高い。こ れに対し, 後者ではゲスト陰イオンの大きさから考えてスルホン 酸基を上下に垂直に配位して取り込まれているものと推定した。

26）慶伊富長，“吸着”，共立出版（1976), p. 56.

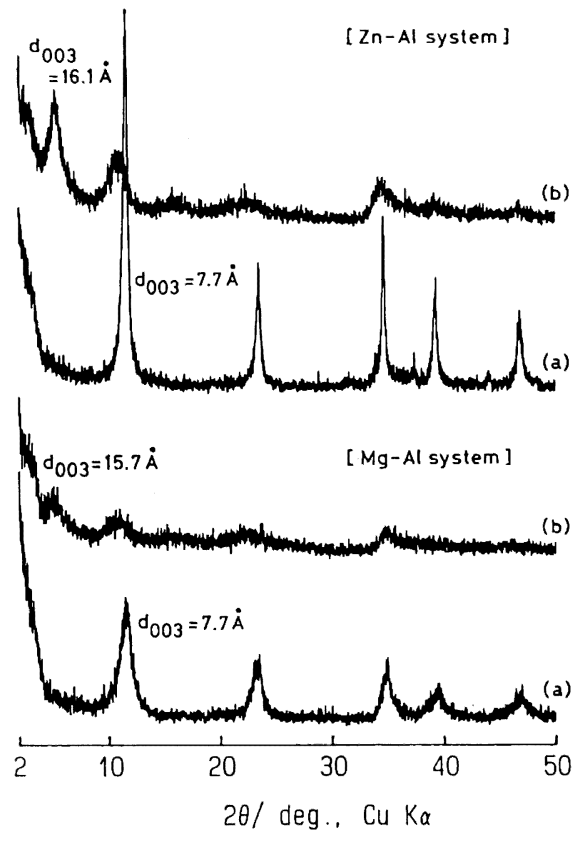

Fig. 3 X-Ray diffraction patterns for the rehydrated products obtained in the NDS solutions

Adsorbed amount $\left(\mathrm{mmol} \cdot \mathrm{mol}^{-1}\right)-($ a ) $6 \sim 10$, (b ) 90 $\sim 120$

結晶化度はいずれの場合でも $\mathrm{Zn}-\mathrm{Al}$ 系の方がより高かった。同 様の傾向が BDS 吸着後の固体生成物の場合にも認められ，層間 距離は, 吸着量の少ない場合には $7.7 \AA$ と同じであり, 吸着量の 多い場合には $11.1 \AA$ と陰イオンのサイズに応じて広くなった。

2 種類の $\mathrm{LDH}$ 熱分解物による芳香族スルホン酸イオンの吸着 特性を調べることにより，基本層の構成元素の違いによる影響を 明らかにすることができた。

本研究は, 平成 3 年度(財)みやき産業科学振興基金からの研究 助成金により実施いたしました。ここに厚く御礼申し上げます。 （1991年 9 月，日本化学会第 62 秋季年会発表） 
- Note-

\title{
Adsorption Property of Aromatic Sulfonate lons by Heat-treated Layered Double Hydroxides
}

\author{
Eiichi Narita*, Toshihide Yamagishi and Kazuko Suzuki \\ Department of Chemical and Biological Engineering, Hachinohe National College \\ of Technology; Uwanotai, Tamonoki, Hachinohe-shi 039-11 Japan
}

The adsorption of 2-naphthol-3, 6-disulfonate (NDS) and $m$-benzenedisulfonate (BDS) ions with the oxide solid solutions prepared by the thermal decomposition of synthetic $\mathrm{Mg}-\mathrm{Al}$ and $\mathrm{Zn}-\mathrm{Al}$ carbonated layered double hydroxides was investigated at $25^{\circ} \mathrm{C}$. Both of the oxides were found to adsorb these anions to reconstruct the layered double hydroxide structure. In the case of the $\mathrm{Mg}-\mathrm{Al}$ system, the Freundlich adsorption isotherms bent at about $0.2 \mathrm{mmol} \cdot \mathrm{dm}^{-3}$ of the equilibrium concentration were obtained. This is due to the fact that the higher equilibrium $\mathrm{pH}$ of $11 \sim 12$ causes a preferential adsorption of $\mathrm{OH}^{-}$in the low concentration region of the sulfonate ions. On the other hand, the Freundlich adorption isotherms obtained in the $\mathrm{Zn}-\mathrm{Al}$ system became straight line because of the lower equilibrium $\mathrm{pH}$ of $9 \sim 10$ (Fig. 2). In both systms, the adsorbed amount of NDS was larger than that of BDS, and the interlayer distance of the solid products varied with the size and adsorbed amount of the guest anions (Fig. 3). 